\title{
Awareness and Factors Associated with Postpartum Modern Contraceptives Use among Women of Reproductive Age in Bukombe District, Geita Region
}

\author{
Immanuel Shayo1, Sia E. Msuya',2,3, Caroline Amour1,2, Michael J. Mahande ${ }^{1,2 *}$ \\ ${ }^{1}$ Kilimanjaro Christian Medical University College, Moshi, Tanzania \\ ${ }^{2}$ Department of Epidemiology \& Biostatistics, Institute of Public Health, Kilimanjaro Christian Medical University College, \\ Moshi, Tanzania \\ ${ }^{3}$ Department of Community Health, Institute of Public Health, Kilimanjaro Christian Medical Centre, Moshi, Tanzania \\ Email: immanuelchance@gmail.com, siamsuya@hotmail.com, lyneamour@gmail.com, *jmmahande@gmail.com
}

How to cite this paper: Shayo, I., Msuya, S.E., Amour, C. and Mahande, M.J. (2020) Awareness and Factors Associated with Postpartum Modern Contraceptives Use among Women of Reproductive Age in Bukombe District, Geita Region. Advances in Sexual Medicine, 10, 71-85.

https://doi.org/10.4236/asm.2020.103005

Received: April 10, 2020

Accepted: May 8, 2020

Published: May 11, 2020

Copyright $\odot 2020$ by author(s) and Scientific Research Publishing Inc. This work is licensed under the Creative Commons Attribution International License (CC BY 4.0).

http://creativecommons.org/licenses/by/4.0/

(c) (i) Open Access

\begin{abstract}
Introduction: Pregnancies that occur during the first year postpartum are more likely to be unplanned. This leads to an increased risk of adverse maternal and perinatal outcomes. However, modern contraceptive use during this period helps to reduce unplanned pregnancies and its associated adverse outcomes. There is scant data on postpartum contraceptives in pastoral communities in Tanzania. This study aimed to assess awareness and factors associated with postpartum modern contraceptives use among women of reproductive age in Bukombe District, Geita Region. Method: A community based cross-sectional study was conducted in a predominant pastoral community of Bukombe district in Geita region in north-western Tanzania from May-June 2018. A total of 511 postpartum women who were in their first year after child birth were studied. A multistage sampling technique was used to select study participants. Data analysis was performed using SPSS version 21. Multivariable logistic regression analysis was used to determine independent predictors of postpartum modern contraceptive use. Results: Most (97.3\%) of the participants were aware about modern contraceptives. The prevalence of postpartum modern contraceptive use was $11.9 \%$. The most frequent used contraceptive method was Implant $6.5 \%$. Majority (75\%) of women started to use the contraceptive at the first three months after delivery. Living in urban $(\mathrm{AOR}=1.84,95 \% \mathrm{CI}: 1.20-3.79)$, business women's $(\mathrm{AOR}=2.34,95 \% \mathrm{CI}$ : 1.31 - 2.28), having last born aged 3 - 4 months (AOR $=3.30,95 \%$ CI: 1.11 9.85 ) and menses resumption ( $\mathrm{AOR}=9.23,95 \% \mathrm{CI}: 3.60$ - 23.72) were associated with postpartum modern contraceptive use. Fear of side effects, poor
\end{abstract}


knowledge about contraceptives, husband restrictions, distance to health facility and availability of contraceptive were the barriers for use of contraceptive use. Conclusion: We found low uptake of postpartum modern contraceptive use in this population. Numerous factors were associated with modern contraceptive use. Therefore, health communication targeting this group is warranted to improve modern contraceptive uptake.

\section{Keywords}

Awareness, Postpartum, Modern Contraceptives Use, Tanzania

\section{Introduction}

Postpartum family planning is an initiation of family planning services within the first twelve months following childbirth [1]. It is aimed at preventing closely spaced and unintended pregnancies [1]. Poor utilization of postpartum modern contraceptives has been associated with unintended pregnancies, induced abortions and increased risk of maternal morbidity and mortality worldwide including Tanzania [2]. Low use of postpartum contraceptives also result to short interpregnancy intervals which increases the risk of induced abortions, miscarriage, preterm births, neonatal and child mortalities, still births and maternal depletion syndrome [2].

Worldwide, about 213.4 million women get pregnant every year, approximately $40 \%$ are unintended, of which about $50 \%$ end up with induced abortions, and $13 \%$ miscarriages [3]. In Africa about 54 million women become pregnant annually, where 19.1 million of them are unintended, resulting to $33 \%$ of abortions [3]. In Tanzania about 2 million women become pregnant every year with an estimate of 1 million are unintended pregnancies [4]. In 2013, about 405,081 cases of induced abortions were reported in Tanzania among women of reproductive age [5].

Several studies have reported low uptake of modern contraceptives in Tanzania [6] [7] [8]. The low contraceptive use has been attributed to desire to conceive in the near future, fear of side effects, lack of freedom to stop the method without involving the health provider, lack of knowledge about the method and its availability [9]; misconceptions, poor accessibility of the method, limited skills among health care providers in modern contraceptive insertions [10], and concerns about the effectiveness of the methods in preventing pregnancy [11]. However, none of these studies have been conducted in the pastoral communities to investigate awareness and uptake of postpartum modern contraceptives where most of women have less contact with health care providers. This exposes these women at risk of unplanned pregnancies.

Postpartum women are at high risk of unplanned pregnancies, especially in their first year after delivery. Adoption of postpartum contraceptives leads not only to reduction in unplanned pregnancies, but also it improves maternal and 
child well-being due to optimal birth spacing. These serious problems could be avoided by the use of modern family planning methods within the immediate or extended postpartum period. Previous investigators have demonstrated that spacing pregnancies for at least two years apart in the developing world could reduce maternal mortality by more than $40 \%$ and under five mortality by $31 \%$ [12].

The reduction of maternal deaths, prevention of unintended and too-early pregnancies is of public health priority in Tanzania. This can be scaled up through counseling on contraceptive methods during prenatal and throughout postpartum periods [13] [14]. The government of Tanzania has made efforts to ensure that postpartum family planning services are integrated in the reproductive and child health services. The National Family Planning Coasted Implementation Program (NFPCIP-2009) plan was also set to identify resources and actions required to make family planning services accessible to all women of reproductive age in order to achieve at least $60 \%$ of contraceptive prevalence by 2015 . According to the TDHS 2015-2016 report, this national target has not been met as the contraception prevalence for married and unmarried women of child bearing age stands at $32 \%$ and $46 \%$ respectively [15].

Although efforts has been made in terms of increasing access to maternal and child care services, no significant improvement has been observed in postpartum contraceptive use within the first year after delivery [15]. Postpartum women still have highest unmet need for family planning in Tanzania ranging from $40 \%$ $75 \%$ as compared to $22 \%$ - $35 \%$ of the general population [16]. In Geita region among predominant pastoral communities where this study was conducted, the modern contraceptive use is low as $13 \%$, unmet need for family planning is $35 \%$ and total fertility rate is 5.5 [16]. Little is known about awareness on postpartum modern contraceptives use and factors influencing its uptake. This study aimed to assess awareness on postpartum modern contraceptive use and its associated factors among women of reproductive age in Bukombe District.

\section{Methods}

\subsection{Study Design and Setting}

A community based cross-sectional study was conducted in a predominant pastoral communities of Bukombe district in Geita region in north-western Tanzania from May-June 2018. Bukombe district is among of the 5 districts of Geita region which is located in the lake zone. It has a population of 224,542, 17 wards; 122 villages, an average of house hold size of 5.9 and fertility rate of 5.5 [17]. Geita is one of the regions with poorest indicators with regards to maternal and new born health in Tanzania. Businesses, small farming and mining are the main activities in the region.

\subsection{Study Population and Sampling Method}

All women of reproductive age ( 15 - 49 years) were included. We excluded women 
who were non-residents in past 6 months and those who had hysterectomy. Multistage sampling process was used to select the study participants. The first stage involved purposive the selection of two divisions out of three divisions in Bukombe district based on their large population sizes. The second stage involved selection of 3 out of 17 wards. Proportionate to size sampling guided selection of wards from each division. The third stage involved random selection of three villages from each of the selected wards where 9 villages were selected. At each village three hamlets were randomly selected and women of reproductive age who gave birth in past one year from the selected hamlets as identified by local leaders were eligible to participate and were invited to participate.

\subsection{Data Collection Method and Tool}

A standardized questionnaire was used to collect data from the study participants through face to face interview. The information collected include: social demographic characteristics, children and reproductive health history and contraceptive methods availability, use and preferences. Seven research assistants employed to assist the data collection (i.e. medical doctors, nurses and social scientists). Research assistants received one day training session involving briefing on the purpose of the study, meaning of terms used in the study and the importance of maintaining ethical standards during data collection process. Prior the data collection, the pilot study was conducted in the nearby community outside the study area to test the validity and reliability of the questionnaire.

\subsection{Study Variables}

The main outcome variable was postpartum modern contraceptives use. The independent variables include; socio-demographic variables such as religion, marital status, education level, employment status and income. Reproductive health variables such as parity, live children, age of the last born, desired number of children, desired birth interval, mode of delivery and place of last delivery were also explored.

\subsection{Ethics Consideration}

Ethical clearance was obtained from Kilimanjaro Christian Medical University College Research Ethics Committee. Permission to carry out the study was obtained from Geita region and Bukombe district administrative authorities. Written consent was obtained from every participant. Anonymity was maintained by using unique identifiers instead of names to maintain confidentiality. Participation was voluntary and the participant's right to withdraw from the study without giving any reason was explained.

\subsection{Statistical Analysis}

Data were analyzed using Statistical Package for the Social Sciences (SPSS) software, version 21. Continuous variables summarized using measure of central ten- 
dency and their respective dispersion. Categorical variables were summarized by proportions and frequencies. Odds ratio and 95\% confidence interval used for factors associated with modern contraceptive use among postpartum women were estimated in multivariable logistic regression model. A p-value of less than $5 \%$ was considered significant.

\section{Results}

\subsection{Characteristics of the Study Participants}

A total of 511 women of reproductive age were studied. The mean (SD) age was 26.48 (6.79) years. Majority 361 (70.7\%) were aged between 25 to 34 years. More than half 304 (59.5) of the participants were involved in pastoral and farming activities, with majority $310(60.6 \%)$ had primary school education level (Table 1).

Table 1. Study participants characteristics $(\mathrm{N}=511)$.

\begin{tabular}{|c|c|c|}
\hline Characteristics & $\mathbf{n}$ & $\%$ \\
\hline \multicolumn{3}{|l|}{ Age (years) } \\
\hline $15-24$ & 72 & 14.1 \\
\hline $25-34$ & 361 & 70.7 \\
\hline $35+$ & 78 & 15.2 \\
\hline Mean (SD) & $26.48(6.79)$ & \\
\hline \multicolumn{3}{|l|}{ Religion } \\
\hline No Religion & 86 & 16.8 \\
\hline Christian & 403 & 78.9 \\
\hline Muslim & 22 & 4.3 \\
\hline \multicolumn{3}{|l|}{ Marital Status } \\
\hline Single/Not in union & 74 & 14.5 \\
\hline Married/Cohabiting & 437 & 85.5 \\
\hline \multicolumn{3}{|l|}{ Education level } \\
\hline No Formal & 171 & 33.5 \\
\hline Primary & 310 & 60.6 \\
\hline Secondary and above & 30 & 5.9 \\
\hline \multicolumn{3}{|l|}{ Occupation } \\
\hline None & 96 & 18.8 \\
\hline Labourer & 22 & 4.3 \\
\hline Business & 89 & 17.4 \\
\hline Farming & 304 & 59.5 \\
\hline \multicolumn{3}{|l|}{ Residence } \\
\hline Rural & 340 & 66.5 \\
\hline Urban & 171 & 33.5 \\
\hline \multicolumn{3}{|l|}{ Income Level (Tsh) } \\
\hline Low $<100,000$ & 415 & 81.2 \\
\hline Normal $\geq 100,000$ & 96 & 18.8 \\
\hline
\end{tabular}




\subsection{Reproductive Health Characteristics of Study Participants}

Majority 379 (76.4\%) of the participants had desire to have more than five children. Majority 307 (72.2\%) wanted to delay the next birth by at least 3 years. Three quarter $384(75.1 \%)$ of the respondents reported to have not resumed menstruation at the time of the study. More than half 225 (44\%) reported ever use of modern contraceptive (Table 2).

\subsection{Awareness and Prevalence of Modern Contraceptive Use}

Most (97.3\%) of the participants were aware about modern contraceptives. More than half 225 (44\%) reported ever use of modern contraceptive. The prevalence of postpartum modern contraceptives was 61 (11.9\%) (Table 2).

\subsection{The Common Contraceptive Methods Used among Postpartum Women}

The most frequently reported modern contraceptives were implant (54\%) and injectable (30\%) while pills (8\%), female sterilization (4\%), intra uterine device and male condoms (2\%) were infrequently reported (Figure 1 ).

\subsection{Factors Associated with Postpartum Modern Contraceptive Use}

In bivariate analysis, some sociodemographic variables such as area of residence (crude odds ratio [COR], 1.85, 95\% CI: $1.21-3.41$ ) and occupation (COR = 2.09, $95 \%$ CI: 1.38 - 3.41) were significantly associated with postpartum contraceptive use. This association remained significant in multivariable analysis where occupation ( $\mathrm{AOR}=2.34,95 \% \mathrm{CI}: 1.31-2.28)$ and living in urban (AOR $=1.84,95 \%$ CI: 1.20 - 3.79) increased women's likelihood of using postpartum contraceptives (Table 3).

In addition, some reproductive factors such as age of last born, desired birth interval and resumption of menstrual were also significantly associated with post-partum contraceptive use in bivariate analysis. After adjustment, last born aged 3 - 4 months (AOR $=3.30,95 \%$ CI: 1.11 - 9.85) and started menstrual periods $(\mathrm{AOR}=9.23,95 \% \mathrm{CI}: 3.60-23.72)$ were associated with modern contraceptive use (Table 4).

\subsection{Challenges Related to Modern Contraceptive Use during Postnatal Period}

A number of challenges were reported to hinder the use of postpartum modern contraceptives. These include fear of side effects (40\%), poor knowledge about contraceptives (29\%), husband restrictions to their wives to use contraceptives (20\%), Distance to the health facility $(9.2 \%)$ and availability of contraceptives methods was infrequently reported (2.1\%) (Figure 2 ).

\section{Discussion}

In this study the prevalence of postpartum modern contraceptive use was low as 
Table 2. Reproductive health characteristics of study participants $(N=511)$.

\begin{tabular}{|c|c|c|}
\hline Characteristics & $\mathbf{n}$ & $\%$ \\
\hline \multicolumn{3}{|l|}{ Parity } \\
\hline$\leq 2$ & 208 & 40.7 \\
\hline $3-4$ & 147 & 28.8 \\
\hline$\geq 5$ & 156 & 30.5 \\
\hline \multicolumn{3}{|l|}{ Live children } \\
\hline$\leq 2$ & 233 & 45.6 \\
\hline $3-4$ & 149 & 29.2 \\
\hline$\geq 5$ & 129 & 25.2 \\
\hline \multicolumn{3}{|l|}{ Age of last born (months) } \\
\hline$\leq 3$ & 162 & 31.7 \\
\hline $4-6$ & 136 & 26.6 \\
\hline $7-12$ & 213 & 41.7 \\
\hline \multicolumn{3}{|l|}{ Desired No. children $(\mathrm{n}=496)$} \\
\hline$\leq 2$ & 14 & 2.8 \\
\hline $3-4$ & 103 & 20.8 \\
\hline$\geq 5$ & 379 & 76.4 \\
\hline \multicolumn{3}{|c|}{ Desired Birth Interval (Years) $(\mathrm{n}=425)$} \\
\hline$\leq 2$ & 118 & 27.8 \\
\hline$\geq 3$ & 307 & 72.2 \\
\hline \multicolumn{3}{|l|}{ Mode of Delivery } \\
\hline Vaginal & 493 & 96.5 \\
\hline Caesarian section & 18 & 3.5 \\
\hline \multicolumn{3}{|l|}{ Place of Delivery } \\
\hline Home & 249 & 48.7 \\
\hline Dispensary/Health Centre & 134 & 26.2 \\
\hline Hospital & 128 & 25.1 \\
\hline \multicolumn{3}{|l|}{ Ever Use modern contraceptive } \\
\hline No & 286 & 56.0 \\
\hline Yes & 225 & 44.0 \\
\hline \multicolumn{3}{|c|}{ Current use modern contraceptive (PPFP) } \\
\hline No & 450 & 88.1 \\
\hline Yes & 61 & 11.9 \\
\hline \multicolumn{3}{|l|}{ Ever heard modern FP } \\
\hline No & 14 & 2.7 \\
\hline Yes & 497 & 97.3 \\
\hline \multicolumn{3}{|l|}{ Resumption menstruation } \\
\hline No & 384 & 75.1 \\
\hline Yes & 127 & 24.9 \\
\hline
\end{tabular}


Table 3. Socio-demographic characteristics associated with postpartum modern contraceptive use $(\mathrm{N}=511)$.

\begin{tabular}{|c|c|c|c|c|c|}
\hline Mothers factors & $\begin{array}{l}\text { Users } \\
\mathrm{N}(\%)\end{array}$ & COR $(95 \% \mathrm{CI})$ & $P$-value & AOR $(95 \% \mathrm{CI})$ & $P$-value \\
\hline \multicolumn{6}{|l|}{ Age (years) } \\
\hline $15-24$ & $3(4.1)$ & 1 & & & \\
\hline $25-34$ & $48(13.3)$ & $1.16(0.30-4.58)$ & 0.828 & $1.21(0.30-5.02)$ & 0.784 \\
\hline $35+$ & $10(12.9)$ & $0.83(0.19-3.75)$ & 0.812 & $0.86(0.18-4.15)$ & 0.856 \\
\hline \multicolumn{6}{|l|}{ Religion } \\
\hline No Religion & $5(8.8)$ & 1 & & & \\
\hline Christian & $45(12.7)$ & $1.18(0.41-3.43)$ & 0.753 & $0.88(0.28-2.81)$ & 0.831 \\
\hline Muslim & $11(50.0)$ & $2.5(0.52-11.89)$ & 0.250 & $1.83(0.33-10.25)$ & 0.487 \\
\hline \multicolumn{6}{|l|}{ Marital Status } \\
\hline Single/Not in union & $17(23.0)$ & 1 & & & \\
\hline Married/Cohabiting & $44(10.0)$ & $0.54(0.27-1.09)$ & 0.088 & $0.71(0.33-1.57)$ & 0.407 \\
\hline \multicolumn{6}{|l|}{ Education level } \\
\hline No Formal & $18(10.5)$ & 1 & & & \\
\hline Primary & $39(12.6)$ & $0.84(0.43-1.66)$ & 0.633 & $0.75(0.37-1.54)$ & 0.434 \\
\hline Secondary and above & $4(13.3)$ & $0.56(0.16-1.94)$ & 0.363 & $0.41(0.11-1.58)$ & 0.196 \\
\hline \multicolumn{6}{|l|}{ Occupation } \\
\hline None & $8(8.3)$ & 1 & & & \\
\hline Labourer & $5(22.7)$ & $2.42(0.62-9.45)$ & 0.103 & $2.56(0.60-11.01)$ & 0.206 \\
\hline Business & $20(22.4)$ & $2.09(1.38-3.41)$ & 0.011 & $2.34(1.31-2.28)$ & 0.038 \\
\hline Farming & $28(9.2)$ & $1.46(0.60-3.57)$ & 0.400 & $1.88(0.74-4.82)$ & 0.187 \\
\hline \multicolumn{6}{|l|}{ Income Level (Tsh) } \\
\hline Low $(<100,000)$ & $44(10.6)$ & $1.36(0.34-1.58)$ & 0.521 & $2.11(0.33-3.02)$ & 0.523 \\
\hline Normal $(\geq 100,000)$ & $17(17.7)$ & $0.43(0.19-2.75)$ & 0.212 & $0.16(0.11-2.15)$ & 0.846 \\
\hline \multicolumn{6}{|l|}{ Residence } \\
\hline Rural & $24(7.1)$ & 1 & & & \\
\hline Urban & $37(21.6)$ & $1.859(1.21-3.41)$ & 0.025 & $1.84(1.20-3.79)$ & 0.045 \\
\hline
\end{tabular}

$11.9 \%$. Factors such as mother's occupation, area of residence, age of last born and resumption of menstrual were significantly associated with postpartum contraceptive use.

The prevalence of postpartum modern contraceptive use in our study was lower compared with the national prevalence of 19\% [18]. The lower prevalence of postpartum contraceptives use in the study area could be explained by high proportion of home deliveries (61\%), coupled with poor attendance to postnatal 
Table 4. Reproductive health characteristics associated with postpartum modern contraceptive use $(\mathrm{N}=511)$.

\begin{tabular}{lccccc}
\hline \multicolumn{1}{c}{ Reproductive factors } & $\begin{array}{c}\text { Users } \\
\text { N (\%) }\end{array}$ & COR (95\%CI) & P-value & AOR (95\% CI) & P-value \\
\hline Parity & & & & & \\
$\leq 2$ & $22(10.58)$ & 1 & & 1 & \\
$3-4$ & $22(14.97)$ & $1.08(0.53-2.23)$ & 0.816 & $1.09(0.39-3.04)$ & 0.862 \\
$\geq 5$ & $17(10.90)$ & $0.67(0.32-1.42)$ & 0.300 & $0.61(0.20-1.88)$ & 0.396
\end{tabular}

Live children

$\begin{array}{lccccc}\leq 2 & 25(10.73) & 1 & & 1 & \\ 3-4 & 21(14.09) & 0.08(0.49-1.97) & 0.955 & 1.09(0.69-2.15) & 0.965 \\ \geq 5 & 15(11.63) & 0.73(0.35-1.55) & 0.411 & 0.99(0.51-3.01) & 0.722\end{array}$

Age of last born(months)

$\begin{array}{lrcccc}\leq 3 & 15(9.26) & 1 & & 1 & \\ 4-6 & 23(16.91) & 2.34(1.07-5.12) & 0.012 & 3.30(1.11-9.85) & 0.032 \\ 7-12 & 23(10.80) & 1.24(0.59-2.63) & 0.564 & 0.63(0.23-1.78) & 0.388\end{array}$

Desired no. children

$\begin{array}{lrcccc}\leq 2 & 2(14.29) & 1 & & 1 & \\ 3-4 & 14(13.59) & 0.75(0.12-4.60) & 0.762 & 0.19(0.02-1.66) & 0.134 \\ \geq 5 & 45(10.82) & 0.78(0.14-4.43) & 0.780 & 0.31(0.04-2.16) & 0.237\end{array}$

Desired Birth Interval

$\begin{array}{cccccc}\leq 2 & 1(0.2) & 1 & & 1 & \\ \geq 3 & 60(14.1) & 9.66(1.25-74.63) & 0.030 & 3.08(0.31-30.75) & 0.338\end{array}$

Mode of Delivery

Vaginal

$59(11.97) \quad 1$

1

Caesarean

$2(13.33) \quad 0.81(0.16-4.15) \quad 0.804 \quad 1.11(0.17-7.38) \quad 0.911$

Place of Delivery

\begin{tabular}{lccccc} 
Home & $17(6.83)$ & 1 & & 1 & \\
Disp/HC & $19(14.50)$ & $1.33(0.62-2.85)$ & 0.460 & $0.79(0.29-2.16)$ & 0.657 \\
Hospital & $25(19.53)$ & $1.75(0.85-3.63)$ & 0.131 & $2.49(0.82-7.62)$ & 0.107 \\
Resumption menstruation & & & & & \\
No & $19(3.76)$ & 1 & & 1 & \\
Yes & $42(8.2)$ & $5.55(2.61-11.82)$ & $<0.001$ & $9.23(3.60-23.72)<0.001$ \\
\hline
\end{tabular}

care in the first 2 days (13\%) in the study area [16]. These leads to missed opportunities for postnatal contraceptive counseling. The postpartum contraceptive use in our study is also lower compared to $28 \%$ that was reported in Uganda 


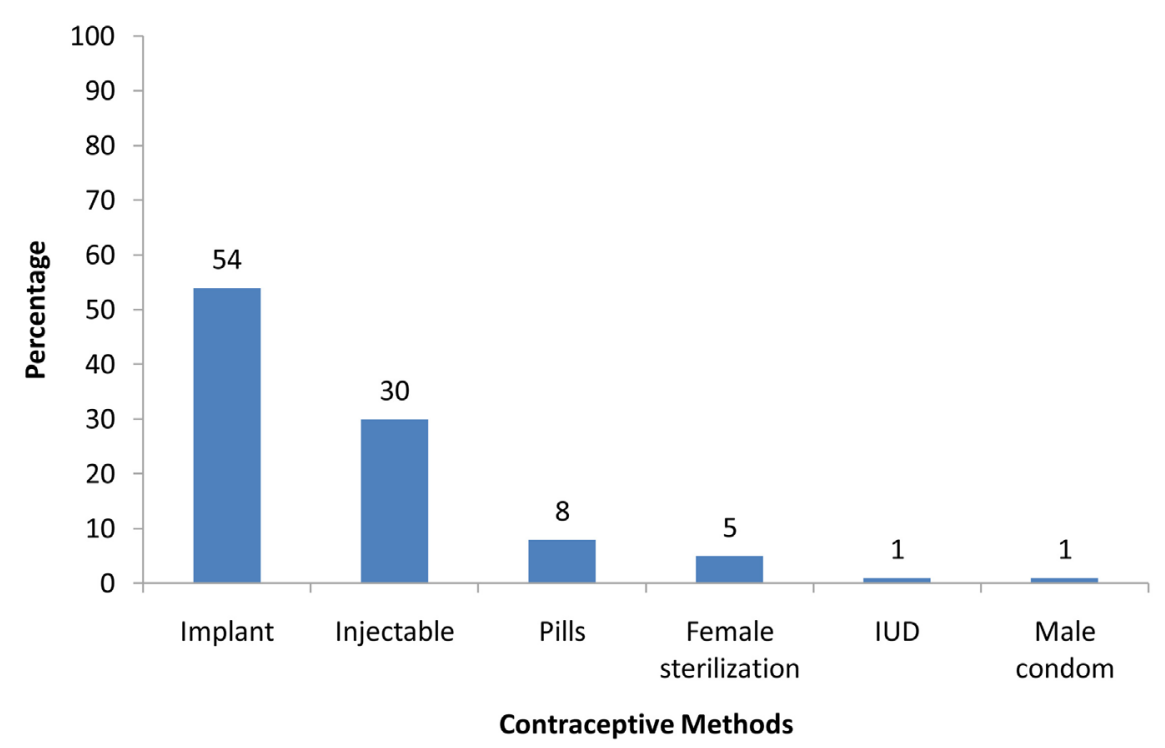

Figure 1. The common contraceptive method among postpartum women $(\mathrm{N}=61)$.

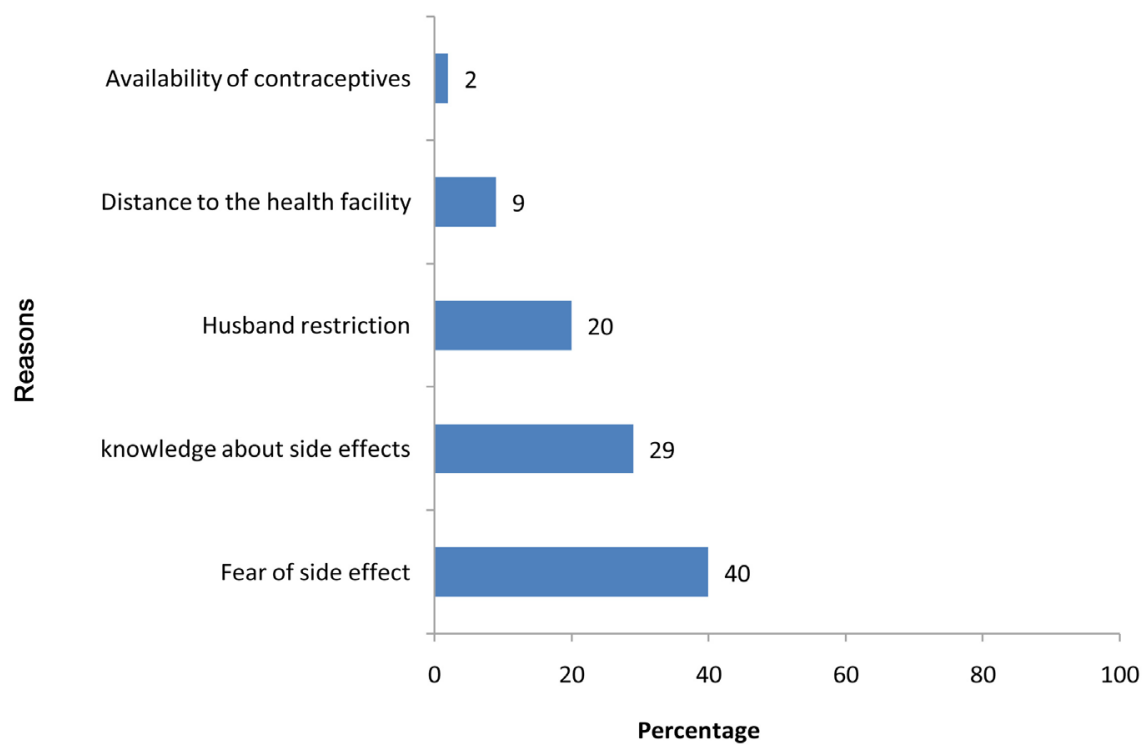

Figure 2. Challenges of postpartum modern contraceptive use.

[19]. The difference in prevalence could be due to the fact that the postpartum women in the former studies were highly motivation to use family planning methods. Our finding suggests that facility delivery remain an important windows of opportunity to provide access to family planning messages and to offer women various contraceptive methods. Therefore, this finding underlines the needs for integration of services within the public sector in order to take advantage of other service delivery to increase the uptake modern contraceptive during the critical postpartum period.

In the present study, the highest proportion of postnatal mothers uses implant contraceptives. This might be due to the fact that implant is not user dependent and may not easily seen by partners [20]. But may also be partly explain wom- 
en's lack of decision making power over their contraceptive choice or their partners' influence [21]. Our finding is in contrast with studies in Ethiopia and Malawi which showed injectable was the most preferable contraceptive [22] [23] [24]. The difference of these findings may be explained by difference in social cultural factors between the two populations. This suggests the need for more emphasize in long acting contraceptives counseling as this will be preferable in this setting where women have little contact with health care providers.

There is a wide variation between developed and developing countries in using some types of contraceptives whereby oral pills and female sterilization are mostly preferred in the United States [7]; while in India male condoms were mostly preferred [6]. Oral pill, injectable and male condoms are more common in Africa and Europe whereas long-acting and permanent methods are more common in Asia and Northern America. Injectables are common in Eastern Africa, Southern Africa, South-Eastern Asia and in some of the poorest countries in Latin America and the Caribbean [25]. The difference could probably be due to social-cultural, economic and geographical variations.

In this study we found that, women's occupation was a significant factor for postpartum modern contraceptives use. Mothers who owned business had 2 times higher odds of using the contraceptives as compared to those in other occupation such as famers and daily walkers. The probable explanation for observed association could be that, mothers who are involved in business activities make an interaction with many people who could have acquired the necessary knowledge to empower them with positive attitude towards the contraceptive use compared to their counterparts in others groups. This finding is consistence with a previous study in Ethiopia [26]. The similarities in finding could be due to social cultural factors and the study settings as these studies were conducted among urban residents and rural residents (predominately pastoral).

We found a significant difference in contraceptive use between Urban and Rural dwellers. Women residing in urban two-fold higher odds of using postpartum contraceptives compared to rural dwellers counterparts. Our finding is consistent with previous studies done in five low income countries [27]. The possible explanation could be that urban women have better access to information, education and health facilities than rural women.

Women whose menses returned after birth had 9 fold higher odds of using post-partum modern contraceptive compared to women on amenorrhea. This finding could be supported by the fact that women may be aware of fertility return when menses resumed. Amenohorric women would perceive less vulnerable to get pregnancy by assuming that amenorrhea would protect against pregnancy irrespective of the postpartum duration. Similar finding was reported in Kenya [28].

The present study also showed that a woman who's their last born aged four to six months had higher odds of using contraceptives compared to other ages. The probable explanation to the observed association could be that most of 
mothers started to experience menstrual resumption at the third and fourth month after delivery.

This study revealed that fear of side effects, poor knowledge about contraceptives, husband restrictions in using contraceptives were the most hindering factors for post-partum contraceptive use. In addition, distance to health facility and availability of the method was among the challenges to use postpartum contraception. This finding is consistent with previous studies done elsewhere [29] [30]. The fear of side effect might be based on their personal experiences or those other women they know or simply on unfounded perception. Some of the women attribute changes in their menstrual cycle to development of diseases in the reproductive system such as uterine fibroids. Prolonged and irregular vaginal bleeding has serious socio-cultural implication for many women.

\subsection{Study Limitations}

Issues of sex and contraceptive use could be a limitation as respondents may be reluctant to provide certain information they consider to be personal. However, we attempted to minimize its effect by assuring the participants that their responses could not be traced to them but only used for scientific purposes. This assurance might have encouraged majority of women to provide answers that reflects their reproductive behavior. The cross-sectional design of this study limited the ability to understand patterns of use or non-use across individuals over time as well as the causal effect relationship.

\subsection{Conclusions}

The postpartum modern contraceptive use in the study area is still low as $12 \%$. The most preferred contraceptive was implant. Occupation, place of residence, age of the last born and menses resumption were associated with modern contraceptive use. Fear of side effects was the most prevalent challenge on contraceptive use.

Adequate counseling on modern contraceptive use (including side effects) during antenatal care, immediate post-delivery and throughout post-partum period is warranted. Provision of better access to information, education and health facilities in rural area may improve uptake of postpartum contraceptives.

\section{Acknowledgements}

This work was supported through the DELTAS Africa Initiative grant \# DEL15-011 to THRiVE-2. The DELTAS Africa Initiative is an independent funding scheme of the African Academy of Sciences (AAS)'s Alliance for Accelerating Excellence in Science in Africa (AESA) and supported by the New Partnership for Africa's Development Planning and Coordinating Agency (NEPAD Agency) with funding from the Wellcome Trust grant \# 107742/Z/15/Z and the UK government. The views expressed in this publication are those of the author(s) and not necessarily those of AAS, NEPAD Agency, Wellcome Trust or the UK gov- 
ernment.

Our sincere gratitude also goes to all women who participated in this study, administrative staff in Geita region, Bukombe District and respective villages for their cooperation and support during the study period.

\section{Conflicts of Interest}

The authors declare no conflicts of interest regarding the publication of this paper.

\section{References}

[1] WHO (2019) Programming Strategies for Postpartum Family Planning. http://www.who.int/reproductivehealth

[2] Jalang, R., Thuita, F., Barasa, S.O. and Njoroge, P. (2017) Determinants of Contraceptive Use among Postpartum Women in a County Hospital in Rural Kenya. BMC Public Health, 17, Article No. 604. https://doi.org/10.1186/s12889-017-4510-6

[3] Sedgh, G., Singh, S. and Hussain, R. (2014) Intended and Unintended Pregnancies Worldwide in 2012 and Recent Trends. Studies in Family Planning, 45, 301-314. https://doi.org/10.1111/j.1728-4465.2014.00393.x

[4] Ministry of Health Community Development Gender Elderly and Children (MoHCDGEC) [Tanzania, Mainland], Ministry of Health (MoH) [Zanzibar], National Bureau of Statistics (NBS) O of the C, Government Statistician (OCGS) and ICF (2010) Tanzania Demographic and Health Survey and Malaria Indicator Survey (TDHS-MIS).

[5] Keogh, S.C., Kimaro, G., Muganyizi, P. and Philbin, J. (2015) Incidence of Induced Abortion and Post-Abortion Care in Tanzania. PLoS ONE, 10, e0133933. https://doi.org/10.1371/journal.pone.0133933

[6] Mahmood, S.E., Srivastava, A., Shrotriya, V.P., Shaifali, I. and Mishra, P. (2011) Original Article Postpartum Contraceptive Use in Rural Bareilly. Indian Journal of Community Health, 23, 56-57. https://doi.org/10.4103/2230-8598.108408

[7] Daniels, K., Daugherty, J., Jones, J., et al. (2015) Current Contraceptive Use and Variation by Selected Characteristics among Women Aged 15-44: United States, 2011-2013. National Health Statistics Reports, No. 86, 1-14.

[8] Fekadu, Y. (2017) Knowledge Attitude and Utilization of Emergency Contraception among Health Science and Medical Students of Arba Minch University, 2015. Journal of Women's Health Care, 6, 383. https://doi.org/10.4172/2167-0420.1000383

[9] Tibaijuka, L., Odongo, R., Welikhe, E., Mukisa, W., Kugonza, L., Busingye, I., et al. (2017) Factors Influencing Use of Long-Acting versus Short-Acting Contraceptive Methods among Reproductive-Age Women in a Resource-Limited Setting. BMC Women's Health, 17, Article No. 25. https://doi.org/10.1186/s12905-017-0382-2

[10] Garrett, C.C., Keogh, L.A., Kavanagh, A., Tomnay, J. and Hocking, J.S. (2015) Understanding the Low Uptake of Long-Acting Reversible Contraception by Young Women in Australia: A Qualitative Study. BMC Women's Health, 15, Article No. 72. https://doi.org/10.1186/s12905-015-0227-9

[11] Kasner, E., Hunter, C.A. and Kariko, K. (2013) Knowledge and Attitudes about Long-Acting Reversible Contraception among Latina Women Who Desire Sterilization. Women's Health Issues, 23, e257-e263.

[12] Cleland, J. and Zulu, E.M. (2011) Family Planning in Sub-Saharan Africa: Progress 
or Stagnation. Bulletin of the World Health Organization, 89, 137-143. https://doi.org/10.2471/BLT.10.077925

[13] Cowman, W., Hardy-fairbanks, A., Endres, J. and Colleen, K. (2013) A Select Issue in the Postpartum Period: Contraception the Importance of Providing Postpartum Contraception Counseling. Proceedings in Obstetrics and Gynecology, 3, 1-15. https://doi.org/10.17077/2154-4751.1198

[14] Lauria, L., Donati, S., Spinelli, A., Bonciani, M. and Grandolfo, M.E. (2014) The Effect of Contraceptive Counselling in the Pre- and Post-Natal Period on Contraceptive Use at Three Months after Delivery among Italian and Immigrant Women.

[15] Adeyemi, A.B., Ijadunola, K.T., Orji, E.O., Kuti, O. and Alabi, M.M. (2005) The Unmet Need for Contraception among Nigerian Women in the First Year PostPartum. The European Journal of Contraception \& Reproductive Health Care, 10, 229-234. https://doi.org/10.1080/13625180500279763

[16] Ministry of Health Community Development Gender Elderly and Children (MoHCDGEC) [Tanzania, Mainland], Ministry of Health (MoH) [Zanzibar], National Bureau of Statistics (NBS) O of the C, Government Statistician (OCGS) and ICF (2016) Tanzania Demographic and Health Survey and Malaria Indicator Survey (TDHS-MIS).

[17] URT. The United Republic of Tanzania (2013) National Bureau of Statistics: 2012 Population and Housing Census Population Distribution by Administrative Areas. Natl Bur Stat Minist Financ, 177, 180.

[18] Welfare, S. (2018) Planning Research Agenda 2013-2018 Tanzania National Family.

[19] Rutaremwa, G., Kabagenyi, A., Wandera, S.O., Jhamba, T., Akiror, E. and Nviiri, H.L. (2015) Predictors of Modern Contraceptive Use during the Postpartum Period among Women in Uganda: A Population-Based Cross Sectional Study Health Behavior, Health Promotion and Society. BMC Public Health, 15, 8-14. https://doi.org/10.1186/s12889-015-1611-y

[20] Adetunji, J.A. (2011) Rising Popularity of Injectable Contraceptives in Sub-Saharan Africa. African Population Studies, 25, 587. https://doi.org/10.11564/25-2-247

[21] Tebeje, B. and Workneh, D. (2017) Prevalence, Perceptions and Factors Contributing to Long Acting Reversible Contraception Use among Family Planning Clients, Jimma Town, Oromiya Region, South-West Ethiopia. Journal of Women's Health Care, 6, 1-10. https://doi.org/10.4172/2167-0420.1000351

[22] Mengesha, Z.B., Worku, A.G., Feleke, S.A., Conde-Agudeloa, A., Belizan, J., Bremanb, R., et al. (2015) Contraceptive Adoption in the Extended Postpartum Period Is Low in Northwest Ethiopia. BMC Pregnancy Childbirth, 15, 160. https://doi.org/10.1186/s12884-015-0598-9

[23] Abraha, T.H., Teferra, A.S. and Gelagay, A.A. (2017) Postpartum Modern Contraceptive Use in Northern Ethiopia: Prevalence and Associated Factors. Epidemiol Health, 39, e2017012. https://doi.org/10.4178/epih.e2017012

[24] Kopp, D.M., Rosenberg, N.E., Stuart, G.S., Miller, W.C., Hosseinipour, C., Bonongwe, P., et al. (2017) Patterns of Contraceptive Adoption, Continuation, and Switching after Delivery among Malawian Women. PLoS ONE, 12, e0170284. https://doi.org/10.1371/journal.pone.0170284

[25] United Nations (2015) Trends in Contraceptive Use Worldwide.

[26] Nigussie, A.T., Girma, D. and Tura, G. (2016) Postpartum Family Planning Utilization and Associated Factors among Women who Gave Birth in the Past 12 Months, Kebribeyah Town, Somali Region, Eastern Ethiopia. Journal of Women's Health Care, 5, 6. https://doi.org/10.4172/2167-0420.1000340 
[27] Pasha, O., Goudar, S.S., Patel, A., Garces, A., Esamai, F., Chomba, E., et al. (2015) Postpartum Contraceptive Use and Unmet Need for Family Planning in Five LowIncome Countries. Reproductive Health, 12, 1-7. https://doi.org/10.1186/1742-4755-12-S2-S11

[28] Ndugwa, R.P., Cleland, J., Madise, N.J., Fotso, J. and Zulu, E.M. (2010) Menstrual Pattern, Sexual Behaviors, and Contraceptive Use among Postpartum Women in Nairobi Urban Slums. Journal of Urban Health: Bulletin of the New York Academy of Medicine, 88, 341-355. https://doi.org/10.1007/s11524-010-9452-6

[29] Sedgh, G. and Hussain, R. (2014) Reasons for Contraceptive Nonuse among Women Having Unmet Need for Contraception in Developing Countries. Studies in Family Planning, 45, 151-169. https://doi.org/10.1111/j.1728-4465.2014.00382.x

[30] Apanga, P.A. and Adam, M.A. (2015) Factors Influencing the Uptake of Family Planning Services in the Talensi District, Ghana. Pan African Medical Journal, 20, 1-9. https://doi.org/10.11604/pamj.2015.20.10.5301 